\title{
RETHINKING THE 'TRUTH' OF IDENTITY: DISSECTING QUEERNESS AND EMO SUBCULTURE IN NETFLIX'S THE UMBRELLA ACADEMY
}

\author{
Pradipta Michella Wibrinda \\ e-mail: pradipta.michella.w@mail.ugm.ac.id
}

\begin{abstract}
Over the years, the presence of LGBTQ+ community in the media has gone through noticeable change. It is a challenge for online streaming services like Netflix to represent as many communities and subcultures as they can, because accessibility comes with more diverse audience. While many LGBTQ+ characters have been put in the spotlight, those who identify beyond binaries are still arguably underrepresented, especially the ones that belong to socially degraded subculture like emo. The Umbrella Academy is a TV show rooted in emo subculture that feature LGBTQ+ superhero characters, Klaus Hargreeves and Vanya Hargreeves, who do not fully associate with the label "gay", "lesbian", or "bisexual". This study employs what Judith Butler asserts, that gender expressions and practices of desire go beyond binaries, to see how emo subculture engages queerness as rejection to rigid classification of gender identities and sexual practices, as well as a tool to oppose conservatism, especially of previous generations. The discussion reveals that contrary to the popular belief that perceives emo as the culture of straight middleclass white boys, the show perceives emo subculture through the characters' rejection to absolute identification. The characters show rejection through clothing, behavior, mannerism, and verbal statements. The characters also show opposition to conservatism, which include traditional gender roles, traditional superhero narratives, masculinefeminine polarity, and the 'truth' of identity.
\end{abstract}

Keywords: emo; LGBTQ+; media; progressive identities; queer

DOI $\quad$ : https://doi.org/10.22146/rubikon.v8i2.69691

Available at https://jurnal.ugm.ac.id/rubikon/article/view/69691

This work is licensed under a Creative Commons Attribution-ShareAlike 4.0 International License

\section{INTRODUCTION}

Looking back ten to thirty years ago, young audience was served with films that featured beloved and iconic protagonists even to this day. Young girls were presented with movies and TV series that gave Cher Horowitz
Article information

Received: 13 August, 2021

Revised: 30 August, 2021

Accepted: 13 September, 2021
(Clueless, 1995), Elle Woods (Legally Blonde, 2001), Kate Heron (Mean Girls, 2004), and Beca Mitchell (Pitch Perfect, 2012) to look up to. Young boys looked up to superheroes like Iron Man, Captain America, Spider-Man, Batman, Superman, and many other characters 
with similar complex backstories. The mentioned main characters are depicted as the underdogs in the wrong crowd before their character developments take in. These main characters aim to seek for acceptance and purposes for being "different", either by fitting in or being formed in a special group. I put the word different in parentheses because despite the underdog status, these popular films still feature normal-looking and normally-behaved characters that are mostly beautiful and thin, handsome and muscular, often rich, ablebodied, cis-gendered, and heterosexual. Additionally, the main-characterization in all the mentioned movies has created genderbased classification. Women-led movies like romantic comedies and chick flicks are dubbed as girl's movies, while superhero or actionfueled movies are dubbed as boy's movies.

What the audience misses from these films is who the actual underdogs are, the outcasts that are more relatable to underrepresented young audience in real life, which somehow rarely made it as the main characters. These characters are typically present to fill in the subplots, like Damian from Mean Girls, Christian from Clueless, Enrique from Legally Blonde, and Cynthia from Pitch Perfect. The similarity of these characters? They are all members of LGBTQ+ community. Additionally, the said characters do not usually act, look, or behave like the main characters or what people considered "normal" Some side characters are also members of underrepresented groups or subcultures, or both. Even as recent as 2021, there is hardly an explicitly LGBTQ+ character that serves as the lead character in popular superhero movies. We see canonically LGBTQ+ characters like Valkyrie from Thor: Ragnarok (2017) and Negasonic Teenage Warhead from Deadpool 2 (2018), but they act as superhero sidekicks. These side characters blur the line between the two classifications, in which given these side characters became main characters, there would be clash between femininity and masculinity. When LGBTQ+ character steps up as the lead, instead of labelling the movie as girl's movie or boy's movie, they are labelled as "gay movie" or "LGBT movie".

As summarized by Dye (2020), representation of LGBTQ+ in media was suppressed initially because several production codes over the years had prohibited inclusion of sex perversion to ensure the films shown in theaters portrayed "correct thinking" to the audience. Homosexuality was practically banned in American theaters until 1982, nearly a decade after homosexuality was no longer considered mental illness in 1974 (p. 52). Even then, most LGBTQ+ characters were put in the background as a statement to support the main character's personality and development. Since the Supreme Court of the United States lifted the bans on same-sex marriage in all fifty states in 2015, discussions on inclusivity in media, especially in movies and TV shows targeted for young audience, have been taking place in many platforms. Netflix as one of the biggest streaming services right now is known for their attempt to be as diverse as possible into their original movies and series. Nowadays we see quite amount of LGBTQ+ characters being the lead of a movie or TV series. However, there are still very few contemporary movies and TV shows with LGBTQ+ lead that is not about being LGBTQ+ or about coming out. The same goes to LGBTQ+ character that is also a part of underrepresented groups, like mental health sufferers, violence survivors, and people with substance use disorder, as well as socially 
Pradipta Michella Wibrinda - Rethinking the 'Truth' of Identity: Dissecting Queerness and Emo Subculture in Netflix's The

Umbrella Academy

degraded subcultures like geek, emo, goth, and nerd.

One of Netflix's original shows that feature main LGBTQ+ characters that are also parts of underrepresented groups is The Umbrella Academy. The show first aired on Netflix in 2019, about seven ex-superhero siblings that once were famous, but grow apart as they get older. The Umbrella Academy's characters, storyline, and aesthetics are built from emo subculture. According to De Boise (2014), the term emo was initially used to identify music with distorted guitar and strained vocals, which was part of hardcore scene in 1980s Washington DC. Emo emerged from American suburbs to articulate opposition to conservatism among middleclass, especially of the parent generation, with emotional lyrics and sound (pp. 226-227). However, the term emo has now been simplified as an umbrella term to identify alternative music or people with interest in alternative music, such as punk, pop-punk, punk rock, grunge, and others, as well as their lifestyle and aesthetics. Their lyrics often bring up issues that mainstream music does not, like broken-home kids, abusive parents, addiction problems, mental health issues, political stances, and others. With its presence over decades, emo is not only limited to preference of genres of music, but it has become an alternative ideology.

The Umbrella Academy is an adaptation of Dark Horse comic series with the same title. The comic series is co-created by Gerard Way, the lead singer of My Chemical Romance, one of the world's biggest bands in the emo scene. The identity of the creator of The Umbrella Academy plays major key in creating the characters. In his interview with Rolling Stone, the singer admitted that the main characters, the Hargreeves siblings, are inspired by My Chemical Romance:

A band especially is a dysfunctional family, so there's little bits of me in all the characters, there's bits of some of the guys in some of those characters and the different roles that we would play in the band and how those roles would change sometimes. We were in a big pressure cooker of fame and notoriety and the characters experience that in the comic and the show (Way, 2019).

Being the manifestation of himself and the other band members, the main characters are portrayed like stereotypical emo. Every single one of the Hargreeves siblings is an adult with alienation problems. They were raised by an abusive and controlling father, were traumatized by violent missions, and had to deal with fame and high expectations at very young age. All of the Hargreeves' personalities are what the viewers, consisting many of Way's fans and people of emo community in general, find relatable. Unlike the Avengers or Justice League members with godly, other-worldly, charming superhero personas, The Umbrella Academy consist of problematic, broke, estranged siblings whose glorious, heroic days are over.

Among seven main characters, there are two that are known to be members of LGBTQ+ community, Klaus Hargreeves and Vanya Hargreeves. While all the siblings are haunted by traumatic childhood and abusive parent, Klaus and Vanya also deal with external problems caused by their sexual and gender identities. What makes Klaus and Vanya different from the aforementioned side characters is that they do not have absolute identification. Neither Klaus nor Vanya identifies as 'gay', 'lesbian' or 'bisexual', although they explicitly have same-sex love 
interests in the series. This resonates with Judith Butler's (1990) words, pertaining what Foucault ironically called 'truth' of sex, that coherent identities and coherent gender norms are produced through regulatory practices ( $\mathrm{p}$. 23). Butler criticized the idea of masculinity and femininity as expressive attributes of male and female as they explain the followings:

The cultural matrix through which gender identity has become intelligible requires that certain kinds of "identities" cannot "exist" - that is, those in which gender does not follow from sex and those in which the practices of desire do not "follow" from either sex or gender. "Follow" in this context is a political relation of entailment instituted by the cultural laws that establish and regulate the shape and meaning of sexuality. Indeed, precisely because certain kinds of "gender identities" fail to conform to those norms of cultural intelligibility, they appear only as developmental failures or logical impossibilities from within that domain (pp. 23-24).

What Butler states belongs to what Warner (2011) identifies as queer theory, as it studies and theorizes gender and sexual practices outside of heterosexuality and challenge the belief that heterosexual practices are normal (p. x-xi).

The objectives of this study are to discuss how the characters from emo TV show portray queerness as the resistance to the 'truth' of identity, as well as to answer the following question: How do the media depict progressive identities as opposition to conservatism through the portrayal of The Umbrella Academy characters?

This study is conducted with the perspective of post-nationalism within the approach of American Studies. As Rowe (2000) asserts, post-nationalism is a critic to the belief that the United States is inherently exceptional than others. Post-nationalism emerged as scholars started to acknowledge various cultural influences that were involved in the change in the social formations of what is called "national culture" (p. 24). Postnationalist concedes that American Studies must admit the presence of socially constructed hierarchies in race, ethnicity, gender, sexuality, and religion. LGBTQ+ community is placed under the gender and sexuality hierarchy as the minor culture in a dominant social system. Thus, queer theory is in scope.

There are several discussions both on gender and sexual identities and on emo subculture prior to this study. Schmitt (2011) explores dress and behavior of the emo subculture, including feminine-masculine clothing and gender and sexual identities. De Boise (2014) analyzes how masculinity and gender equality evolve in emo subculture. Discourse on LGBTQ+ youth in media like films are discussed Dye's (2020) article about how coming-out and reactions to coming-out are perceived in contemporary movies. These previous studies, however, have not yet specifically covered how nonidentifying/queer individuals within emo subculture are depicted in mainstream media like Netflix, especially as characters with esteemed roles like superheroes.

The data for this study are obtained by examining the presentation of the characters in Netflix series The Umbrella Academy, including their dialogs, visuals, and behaviors. As of September 2021, the show consists of two seasons, with ten episodes in each season. Thus, both airing seasons are covered in this study as the primary data. Sources like 
journals, books, and online publications are used to support the purpose of this study.

To fulfill its objectives, this study is conducted using qualitative research. Creswell (1997) defines qualitative research as an inquiry process of understanding based on distinct methodological traditions of inquiry that explore a social or human problem (p. 44). In this case, Klaus Hargreeves and Vanya Hargreeves are fictional characters that represent humans, and Netflix's The Umbrella Academy acts as the media. Thus, exploring the depiction of gender and sexual identities of the characters is considered a process of understanding social and human problem.

\section{DISCUSSION}

Before diving into the discussion on Klaus and Vanya, it is important to underline that family and upbringing are two major contributing factors on the characters' developments. Thus, understanding the context of this show is necessary. The Hargreeves siblings do not have the most conventional start in life. They were born on the same day in different places around the world, to women with no sign of pregnancy before. They were adopted by eccentric billionaire Sir Reginald Hargreeves when they were babies. Reginald then formed a group of child superheroes called The Umbrella Academy, where he controlled and trained them as kids and threw them under the spotlight. Unlike other superhero movies and TV series, one should expect no heroic actions of saving millions of lives or protecting cities with their power as the center of the story, as usually seen in Marvel or DC movies. It mainly highlights the internal conflicts in the family while using their remaining power and solidarity to prevent the upcoming apocalypse.
The story starts later when they are all thirty years old, about fifteen years after the death of one of their siblings, Ben (Number Six), which caused the fallout of the team. The estranged siblings are forced to reunite after the news of their father's death. It is essential to highlight once again that Klaus and Vanya are not the only characters with alienation problem. The rest of the siblings are also considered the underdogs outside their family. They grew up under the confinement of his adoptive father who constantly manipulated and forced them into dangerous missions, which are too deadly and traumatizing for children. Their only mother figure is a robot maid, who takes care of the siblings more humanly than Reginald does. Reginald does not even bother giving them names and only calls them by number. Those practices of abuse and dehumanization can be summarized in one sentence as Reginald's dialogue as follows: "Despite years of training and weeks of preparation, you allowed Number Six to die on this mission," (s. 2, ep. 10, 01:32).

The Hargreeves siblings are adults when the show starts, but the times that were filled with violence, mental and verbal abuse, disappearance of Number Five, and the constant blame over Ben's death happened in their teenage years, which shaped their grey moralities as they grew up. For context, Luther (Number One) is isolated by his father and releases his anger through physical fights. $\mathrm{He}$ is the only one who never actually left the academy. Diego (Number Two) develops superhero complex from years of his father's pressure. Allison (Number Three) is a divorced woman who misuses her mindcontrolling power to get anything she wants. Klaus (Number Four) has serious substance abuse problem and post-traumatic stress disorder (PTSD) since Reginald always 
pushed his abilities to communicate with the dead. Number Five had been trapped in the future and came back as a 58-year-old assassin in a 13-year-old body, so despite being the oldest and the smartest, his physical appearance makes it hard for his siblings to take him seriously. Ben (Number Six) is a ghost who can only communicate with and be visible to Klaus, who is rarely sober. Lastly, Vanya (Number Seven), has been told by her father that she is ordinary her whole life. Reginald also makes the other siblings believe that Vanya does not have power, except Allison, who was forced to mind-control her into thinking that she is powerless when, in fact, Vanya's ability is the most powerful and most dangerous. This makes Vanya the most distant sibling among the others, because she has always been excluded from trainings and missions.

Each of the siblings has different coping mechanism, but they all, except Luther, end up quitting the academy, leading to estrangement from each other and from society in general to live as ordinary people. Their feelings of vulnerability and willingness to express their post-rebellion identity fit what Bailey (2005) describes as emo (p. 1), with Reginald as what De Boise (2014) calls the parent generation (p. 227). Their expression, according to Schmitt (2011), taps the social dissatisfaction and alienation, which continue and are modified in emo in the solitude and loneliness (p. 11). The portrayal of the Hargreeves as the underdogs signifies as bold statement to audience that they are different than the others. As LGBTQ+ characters, however, Klaus and Vanya are depicted to be the most relevant to emo subculture.

\section{Queerness as a Rejection to Absolute Identification}

Emo subculture can seem very heteronormative at a glance. Due to its history rooting in groups of middle-class Caucasian boys in the suburbs, emo subculture is often associated with masculinity and heteronormative culture. Columnist Sherman (2020), criticizes the presence of sexism and toxic masculinity in emo subculture, which has been infiltrated by gender existentialists and unbalanced power that celebrate cis-male biology, which "informs expressions of masculinity in emo performance". Furthermore, with its similarity to rock scene, emo scene which consists of loud music, maledominated artists, dark attires, and lyrics about heterosexual relationships, creates a belief that makes emo subculture seem as if it belongs in the heterosexual men's realm. Meanwhile, LGBTQ+ men is often highly associated with "less masculine" subcultures like boybands, musical theater, and pop music. The genderbased classification shows it presence once again, constructing gender-based stereotypes in the music genres itself, as well as their respective culture and aesthetics.

The ' $Q$ ' in LGBTQ+ can stand for both queer and questioning. There is empirical evidence that contemporary teenagers are "post-gay" (Russell et al., 2009, p. 888). It is a state where non-heterosexual youths conceive themselves as questioning, queer, exploring, providing their own labels, or not labelling themselves at all. Although in different places and times the term 'queer' is often used as a slur to mock someone who is assumedly homosexual, the term itself generally signifies as a broader term that is used to identify various people within the spectrum of nonheterosexuality. 
It is important to acknowledge that although both Klaus and Vanya are no longer self-discovering teenagers, there is always room for exploration for practices of desire and subversion of identity at any age (Butler, 1990, p. 99-100). As outlined previously, the creator of the show is an important element in the making of the story and the characters in The Umbrella Academy. The creator of the show, Gerard Way, does not fully associate himself with masculinity, as quoted from his statement in Reddit AMA (2014) as follows:

I have always identified a fair amount with the female gender, and began at a certain point in [My Chemical Romance] to express this through my look and performance style. So it's no surprise that all of my inspirations and style influences were pushing gender boundaries. [...] Masculinity to me has always made me feel like it wasn't right for me." (Way, 2014).

Discussions about sexuality and gender identities are very casual in this show. Despite being involved in same-sex relationships, both Klaus and Vanya, never explicitly put labels on themselves. It is mentioned in the show that Klaus also has consensual sex with a woman in season two. It is also shown that Klaus can be polyamorous as well, which means to get romantically and/or sexually involved with more than one person simultaneously. Vanya's love interest in the entire season one is a man, while in season two her love interest is a woman. Their siblings, on the other hand, never question, label, or talk about Klaus and Vanya's sexuality either, for example, as seen in the following dialog:

[Diego:] Is this about conjuring the one you lost? What was her name?

[Klaus:] His name was Dave. We soldiered together in the A Shau Valley, in the Mountain of the Crouching Beast.
[Diego:] Well, Dave must have been a very special person, to put up with all your weird-ass shit. (s. 1, ep. 6, 28:25)

Diego's line in the dialog, assuming Klaus was romantically or sexually involved with a woman, shows the absence of definition in Klaus' sexuality. This can also be seen as the creators' way of telling the audience that there is no queer-coding regarding Klaus' character, pointing out to media's recognition of the presence of post-gay.

The answer to the questions on why queer and emo subculture are close is the presence of transgression. This is contrary to the belief that perceives emo as the culture of straight middle-class white boys. The transgression in the series can be seen in the first episode of season one. Before the team disbands, the Hargreeves are monitored 24 hours a day by their father and his assistant. Reginald clamors them with tight schedule and strict rules, that the siblings cannot make their own decisions. They are required to wear uniforms even inside the house. Even their pajamas are coordinated. That is why after they leave, Klaus and Vanya are through fulfilling rules, because Reginald's confinement, which represents traditional societal rules in real life that lead people to think that there are certain ways to exist, does not apply outside the academy. This resonates what Schmitt (2011) says about emo as a subculture that

consists of male and female youths transgressing beyond standard dress and expectations, often presenting androgynous look as male and female "emo kids" share similar hair- and clothing styles. Though not specifically queer in gendered and/or sexual identification, the term "emo", like the term "queer", resists definition and is consistently in flux (p. 3). 
The way Klaus and Vanya oppose traditional norms is seen through both of their appearance and behavior. On the first appearance of Klaus in the introduction scene, Klaus is seen walking out of a rehabilitation center with the remnant of eyeliner on his eyes, channeling the signature looks of alternative musicians that are known for their excessive use of eye makeup like Gerard Way himself, Avril Lavigne, and Billie Joe Armstrong. This small detail on Klaus' look is not just a minor trivial matter, but a major part of his expression because, unlike the musicians, Klaus' look is not intended for performance. For someone who just left a rehabilitation center after quite some time, Klaus keeping make up set with him, and using it especially, shows that he makes a bold statement that he is who he wants him to be through his appearance. In many occasions he is also seen wearing feminine clothing items like tight leather pants, high-heeled boots, skirts, crop tees, hair pins, furry coat, and scarves. Since the show also involves time travels, Klaus' appearance changes as well to adjust to what is considered more appropriate in the era. In the first season, Klaus accidentally time-travels to 1968 Vietnam, where he meets his love interest Dave. He fights in the war, wears masculine clothing and shows masculine behavior just as what a soldier is like in general. When he comes back to 2019, Klaus' clothing and behavior mostly sit on the grey area. Sometimes they switch between feminine and masculine, and sometimes the combination of both. In season two, which is set in 1963 Dallas, Klaus is seen again adjusting to clothing that is more appropriate for the time period, since blatant queerness is not as acceptable as it is in 2019.

The same goes with Vanya. Since her first appearance until the end of the latest season, Vanya's clothing is always masculine or gender-neutral, except in the flashback scenes when she still has to wear uniforms. Post-academy Vanya is always seen wearing sweaters, men's shirts, coats, and loose fit jeans. Even in formal occasions, Vanya opts for wearing suits rather than formal dresses. I find Vanya's appearance and mannerism resemble what Bailey et al. (2002) describes as tomboy, where girls are "more likely than other girls to prefer associating with boys". This, Bailey adds, shows the presence of two areas in gender identity, one is the degree of comfort with the assigned sex and the other is the desire to be a member of other sex. (p. 333-334). In regards to femininity and masculinity traits in practices of desire, Vanya's roles switch, depending on who she is with. Referring to Bem's Sex Role Inventory (1974, p. 156), Vanya shows more feminine traits like gentle, shy, sensitive, soft spoken, gullible, and warm when she is with a man. Meanwhile, with a woman, she shows more masculine traits like analytical, assertive, dominant, willing to take stands, and willing to take risks, especially when Vanya's love interest is a married woman living through the 60s. The way Vanya positions herself in relationships amplifies her fluidity in gender and sexual practices.

Now this is a reminder that so far, in the first two seasons of The Umbrella Academy, Vanya is referred to with she/her pronouns. However, the use of she/her and he/him pronouns does not always imply absolute binary identification on someone's gender identity. It is also crucial to acknowledge that Elliot Page, the actor who plays Vanya in The Umbrella Academy, came out as a transgender in December 2020. In today's climate, where the identity of a performer in the media is important to correctly represent particular 
group or community, it becomes principal to not always fully separate a fictional character and who portrays it. Thus, it is highly possible for the show to explore more on Vanya's practices of desire, as well as her gender identity.

Klaus and Vanya's non-traditional practices of desire recall Butler's statement in the previous chapter where they criticize the idea of coherent identities and gender norms. The characters' actions, choices, and appearances have made statement that their gender and sexual identities are, in fact, not definitive. The rejection of traditional social rules on genders and sexuality has opened up more possibilities to what 'truth' of identity really is. It has opened the doors to discussions on the presence of gender and sexual identities beyond the binaries, which then becomes recognized and eventually accepted in the society to the point where actual people with such identification are acknowledged and represented in the media.

\section{Progressive Identity as an Opposition to Conservatism}

After a brief discussion on underrepresented groups in media in the previous chapter, let us visit the year 2018, where Black Panther was released. After the presence of several black superheroes serving as the main characters' sidekicks many years prior, Black Panther created historical momentum in film industry as the first superhero movie that features black superhero as the titular character. For once, a movie with predominantly black actors is not widely labelled as "black movie" as they did The Color Purple (1985), Dream Girls (2006), and Straight Outta Compton (2015). Following the release of Black Panther, the talk of representation in the media once again arose, this time about a movie featuring black main character that is not about being black. Black Panther is a "superhero movie".

The success of Black Panther has broadened the road to normalization of the idea that any individual from minority groups can be a superhero. Like Black Panther, The Umbrella Academy also seeks out the way to put characters from various ethnicities, genders, and sexual orientations to the spotlight. However, when a character is not especially from dominant culture, they have to work harder to live up to certain standards to fulfill the "traditional" superhero characteristics: tall, beautiful and sexy, macho and muscular, smart, strong, brave, and morally straight. According to Moriarty (2013), although personifications of superheroes change over the years, their main characteristics have remained the same (p. 6). Di Paolo (2011) describes superhero narratives as follows:

Superhero narratives, as they are traditionally understood, involve colourfully garbed heroic icons that demonstrate uncanny strength, intelligence, supernatural powers, and near infallibility. (p.2)

The visual depiction of superheroes has always been formulaic. Popular male superheroes, including Black Panther, have mostly met the traditional standards of superhero narratives that Di Paolo explicates. Male superheroes are often portrayed shirtless or flexing their muscles on screen to show their masculinity, showing leadership, competing on who is more skilled in combat, stronger, and more intelligent, like what we see between Iron Man, Captain America, and Winter Soldier in Captain America: Civil War (2016) and Batman and Superman in Batman v 
Superman: Dawn of Justice (2016), constructing a popular belief that male superheroes are always macho. Meanwhile, as minorities in a male-dominated culture, female superheroes have to work harder to fulfill certain standards to get what it takes to what makes a superhero a hero. Following the release of Captain Marvel (2019), the movie was widely criticized for "forcing feminism" by introducing female superhero that is portrayed as strong and powerful rather than sexy or pretty like her predecessor Wonder Woman and Black Widow. Female superheroes are often oversexualized, with their skin-tight suits and their hour-glass feature. In some cases, strong female superheroes showing off "badassery" are dubbed as the symbol of feminism.

Then, what standards do queer heroes like Klaus and Vanya have to satisfy? The portrayal of Klaus and Vanya's progressive identities is used by the media as one of the tools to oppose traditional social rules, both in superhero narratives and social settings. With shows like The Umbrella Academy, comic book fans are served with fresh, alternative superhero story that does not only emphasize on power and being a hero, but also highlights how reality is for those heroes as human beings, along with their human problems. With their respective problems, the Hargreeves develop sense of belonging after finding their common ground post-academy. This fits what Way (2020) describes as subversion, where an alternate group does not get stopped by the rules of society (p. 114). For Klaus and Vanya especially, they are the furthest among the other Hargreeves from most of the traditional superhero characteristics. Luther, Diego, and Allison still fulfill some of the traditional superhero visuals: tall, muscular, attractive, fast, and strong. Number Five looks prim and dapper, is very smart and has great leadership quality. Klaus and Vanya, on the other hand, can relate to each other when it comes to their self-esteem compared to their siblings, especially in heroic actions. The following dialog is an example of what Feenstra et al. (2020) describes as "impostor syndrome", where some individuals feel as if they were inferior because they were parts of marginalized groups, but ended up in esteemed roles and position (p. 1):

[Klaus:] You can count me out.

[Allison:] Klaus!

[Klaus:] What? You guys should save her. You're great at all the hero shit. Listen, Vanya would understand, 'cause she has realistic expectations of what I am. (s. 2, ep. 9, 00:26)

Klaus and Vanya's inferiority is also depicted in their presentation on screen, including their appearance and choices. Klaus is lean and unkempt, a drug addict, a hippie, and lazy. Vanya is petite and does not have typical superheroine body. Vanya wears men's shirts instead of tight leather suit, but at the same time she is not macho, and despite possessing the strongest power, Vanya is not skilled in physical fights or combat strategies like her sister Allison. Instead of showing strength, intelligence, and badassery, Klaus and Vanya tend to avoid using their powers, look sad, stressed out, and tired most of the time. Furthermore, Klaus and Vanya are the only siblings who have to deal with drugs. As Reginald's way to suppress Vanya's power, he manipulates her into thinking that she is sick, so she has to take medication since as long as she can remember. Meanwhile Klaus is addicted to drugs because he wants to block his ability to see the dead. At one point, both withdraw from drugs and medication for separate reasons. Klaus sobers up when attempting to communicate with his deceased 
Pradipta Michella Wibrinda - Rethinking the 'Truth' of Identity: Dissecting Queerness and Emo Subculture in Netflix's The

Umbrella Academy

father, while Vanya was incited by her exboyfriend to quit medication. As they get off drugs, it gets harder to control their power, especially for Vanya. Their suffering puts them in the same boat, pulling them even closer to solitude and loneliness compared to their other siblings.

While the rest of the siblings show willingness to save the world, Klaus and Vanya would mostly rather be left out. In some occasions, while the others, despite their differences, try their best to cooperate, Klaus and Vanya put their own interests above the others, causing the missions to lag. Lastly, Klaus and Vanya are too ambiguous to be associated with machoism or symbol of feminism, or even be associated with superhero at all.

In social settings, Klaus and Vanya's gender and sexual identities are considered minority. In the incorrect places and times, people consider them not normal, or even wrong. In 2019 setting, individuals like Klaus and Vanya are arguably accepted. However, as season two is entirely set in 1960s, Klaus and Vanya are used as media's tools to oppose conservatism. In 1963, Klaus is set to trace back Dave before he signs up to the military to prevent him from dying in the Vietnam War, and Vanya is set to build a relationship with Sissy, a woman who is married to typical 60 s conservative husband. This storyline is also used on their other sister, Allison, who is a black woman. The creators of the show utilize the "what-if" storyline by sending off marginalized people with 2019 mindset and upbringing to 1960s Texas, a red Southern state, where homosexuality is still widely despised and civil rights movements are still taking place.
The opposition to conservatism is indivisible with the show's emo root. Emo subculture is known for their inclusivity of all races, nationalities, sexualities, and genders. Recently, the members of the community, including the musicians, also participate in raising voices and awareness for social and political issues like climate change, equality, Black Lives Matter, and impeachment of President Trump. Klaus and Vanya's opposition to conservatism is not as obvious as Allison's, who jumps right into the civil rights movement by doing sit-ins and marches. Klaus and Vanya are faced with conservative individuals, but their opposition is more a personal matter rather than a collective interest.

In opposing conservatism, Vanya is more subtle than Klaus. Sissy's husband compares Vanya to a sick cow that can cause a plague, implying that homosexuality is a transmissible disease. Although Vanya shows her opposition, she does not do anything else other than expressing disapproval (s2, ep. 7, 20:24). Since women are seen inferior in the 1960s, Vanya is aware that further confrontation may put her and Sissy in danger because their position as women put them in powerlessness. Instead of fighting Carl in attempt to be with Sissy, Vanya tries to save her from an unhappy marriage by plotting to take Sissy with her to 2019, where they do not have to hide anything anymore or pretend to be people they are not. Her opposition to conservatism can be seen through her dialog with Sissy as follows:

[Vanya:] We need to leave before Carl gets back.

[Sissy:] I need to talk to him first.

[Vanya:] There isn't enough time.

[Sissy:] He's my husband. I owe him an explanation.

[Vanya:] You don't owe him anything! (s. 2, eps. 7, 36:17) 
Her lines show a rejection towards Sissy's concept of traditional gender roles in marriage, where she thinks she needs Carl to know everything she does because he is her husband, no matter how bad he treats her. Vanya tries to push her 2019 mindset to Sissy that women do not owe men anything, even when he is the husband.

Klaus and Vanya show their opposition to conservatism in their different ways. While Vanya is more cautious with how people in the 60s see same-sex relationships, Klaus is more impetuous. He does not try to hide his queerness even in public. He also openly expresses his heartfelt confession to young Dave, who does not know who Klaus is yet, in front of Dave's conservative uncle Brian. Klaus is also shown rejecting the binary polarity, as seen in the following dialog between him and Brian after his homophobic remarks:

[Brian:] Do you know this... clown?

[Dave:] Um, he bought pink paint at the store.

[Brian:] Pink paint. Makes sense.

[Klaus:] You know, pink can actually be masculine in the right setting. (s.2, ep. 4, $15: 45)$

Apart of expressing himself openly, he also promotes normalization of sexual practices outside of heterosexuality. Using his knowledge about the future, he gains hundreds of followers to start a cult and make them believe that he is a prophet. He uses his influence to encourage the propriety of unconventional sex practices that are frowned upon at that time, like same-sex intercourse, swingers, and polyamory.

Queer characters like Klaus and Vanya, especially in superhero films, are burdened with quite amount of challenge. Netflix, as one of supposedly progressive media in the present, has demonstrated its attempt to recognize the presence of progressive identities and the rejection of traditional social norms that some younger generations consider outdated. Netlfix has its fair share to feature them in their original works, including The Umbrella Academy. As kids look upon a superhero as the epitome of a good person, there would always be rejection especially from parents' generation who disagree, because in reality, there are always opposing groups regarding what media promote as diversity and representations. Nevertheless, although they are given the choice to not be parts of The Umbrella Academy, Klaus and Vanya stay with their family. At the end of the day, no matter what they identify with, Klaus and Vanya are still superheroes who save the world.

\section{CONCLUSION}

The presence of queerness and emo subculture is the result of collective voices among youth with the same dissatisfaction in traditional social setting and/or dominating culture. This study finds that emo subculture is perceived in The Umbrella Academy by validating characters with progressive sexual and gender identities to depict subversion or alternative groups that do not follow traditional social rules. This is contrary to the popular assumption that associates emo subculture with heteronormativity and specifically masculinity.

The existence of group of people that do not identify themselves with certain gender and sexual identity, as well as self-discovering people who long for approval, create a comfort space. It is a progress for these individuals that their representations are featured in popular 
media, especially when one of the creators, who is a prominent figure in the said subculture, is given the space and opportunity to embody their works. Movements on equality in the past decades definitely have its impacts in representation of LGBTQ+. Not only is that homosexuality no longer perceived as something wrong or taboo, the presence of progressive gender and sexual identity is starting to get its recognition as well due to several factors like the creators of the work itself and due to the demand from audience.

Nowadays, LGBTQ+ characters start getting their roles as the hero, the captain, the teacher, or even the killer, instead of just "the gay one", which could possibly be invalidating for characters who identify as other labels. Of course there is still a long way to go, considering many films still use stereotypes to portray LGBTQ+ characters. Nevertheless, movies and TV shows are powerful tools that can educate and at the same time provide entertainment. Since the existence of online streaming platforms makes it easier to access films today, the range of the audience that can consume these films have broadened. The more diversity that is present in the audience, the more challenging it is for film industries to represent as many groups and communities as possible. Movies and TV shows can be used as media to show acknowledgement to the presence of underrepresented communities and subcultures. Besides, in the era of technology and internet, it is possible for film industries to utilize their works as platforms to oppose traditional social rules, as a way to educate their viewers that not everything is black and white, even in the most subtle ways. Gender and sexual identities are fluid, and traditional social rules are politically and culturally constructed beliefs that can be rethought and reevaluated. With the movies and TV shows that are presented in accessible media, young audience should be able to feel validated, seen, and accepted for the way they identify and express themselves.

\section{REFERENCES}

Bailey, B. (2005). Emo music and youth subculture. In Steinberg, P., Parmar \& Richards [Eds.]. Encyclopedia of contemporary youth culture. Greenwood Press.

Bailey, J., Bechtold, K. \& Berenbaum, S. (2002). Who are tomboys and why should we study them?. Archives of sexual behavior, 31(4), 333-341. DOI: 10.1023/A:1016272209463

Bem, S. (1974). The measurement of psychological androgyny. Journal of consulting and cynical psychology, 42(2),

155-162.

https://psycnet.apa.org/doi/10.1037/h0 $\underline{036215}$

Butler, J. (1990). Gender trouble: Feminism and subversion of identity. Routledge.

Creswell, J. (1997). Qualitative inquiry \& research design: Choosing among five approaches. SAGE Publications.

De Boise, S. (2014). Cheer up emo kid: Rethinking the 'crisis of masculinity' in emo. Popular Music, 33(2), 225-242. https://www.jstor.org/stable/24736806

Di Paolo, M. (2011). War, politics and superheroes: Ethics and propaganda in comics and film. McFarland \& Company.

Dye, S. (2020). Representing sexuality: An analysis of coming out in contemporary film. Elon journal of undergraduate research in communications, 11(2), 5158. Retrieved from https://www.elon.edu/u/academics/co mmunications/journal/archive/fall$\underline{2020 /}$

Feenstra, S., Begeny, C., Ryan, M. (2020). Contextualizing the impostor 
"Syndrome". Frontiers in psychology, 11.

https://doi.org/10.3389/fpsyg.2020.575 $\underline{024}$

Moriarty, A. (2013). Superheroes and society: Tracing the socio-cultural trajectory of American mainstream superheroes [Dissertation].

https://www.scss.tcd.ie/publications/th eses/diss/2013/TCD-SCSSDISSERTATION-2013-057.pdf

Rowe, J. (2000). Post-Nationalist American Studies. UC Press.

Russel, S., Clarke, T. \& Clary, J. (2009). Are teens "post-gay"? Contemporary adolescents' sexual identity labels. Journal of Youth and Adolescence, 38, 884-890. Retrieved from https://doi.org/10.1007/s10964-0089388-2

Schmitt, K. (2011). Exploring dress and behavior of the emo subculture. Dissertations, theses and capstone projects, 465. https://digitalcommons.kennesaw.edu/ etd/465

Sherman, M. (2020, October 12). The miserable business of emo masculinity. Jezebel. https://jezebel.com/themiserable-business-of-emomasculinity-1845304316

Warner, M. (1993). Fear of queer planet: Queer politics and social theory. University of Minnesota Press.

Way, G. (2019, February 22). How the dysfunction of my chemical romance inspired 'The Umbrella Academy' ( $C$. Holmes, Interviewer). Rolling Stone. https://www.rollingstone.com/tv/tvfeatures/gerard-way-umbrellaacademy-my-chemical-romanceinterview-797368/

Way, G. (2014, October 3). 15 Things we learn about Gerard Way's Reddit AMA (Emily, Editor). Kerrang Magazine. https://web.archive.org/web/20190512 015035/https://www.kerrang.com/2345 2/15-things-learned-gerard-waysreddit-ama/

Way, G., Bá, G., Blackman, S. (Executive Producers). (2019-present). The Umbrella Academy [TV Series]. Borderline Entertainment, Dark Horse Entertainment, Universal Cable Productions; Netflix. https://www.netflix.com/us/title/80186 863? $\mathrm{s}=$ a\&trkid $=13747225 \& \mathrm{t}=$ wha\& $\mathrm{vl}$ ang=en\&clip=81477197

Way, L. (2021). Punk is just a state of mind: Exploring what punk means to older punk women. The Sociological Review, 69(1), 107-122. https://doi.org/10.1177/0038026120946 $\underline{666}$ 